\title{
Improving the economic and humanistic outcomes for diabetic patients: making a case for employer- sponsored medication therapy management
}

This article was published in the following Dove Press journal:

ClinicoEconomics and Outcomes Research

10 April 2013

Number of times this article has been viewed

\author{
Sharrel L Pinto \\ Jinender Kumar \\ Gautam Partha \\ Robert A Bechtol \\ The Pharmaceutical Care and \\ Outcomes Research Laboratory, \\ Department of Pharmacy \\ Practice, College of Pharmacy \\ and Pharmaceutical Sciences, \\ The University of Toledo, \\ Toledo, $\mathrm{OH}$
}

Correspondence: Sharrel L Pinto Department of Pharmacy Practice, College of Pharmacy and Pharmaceutical Sciences, The University of Toledo, Mail Stop I0I3, 3000 Arlington Avenue, Toledo, $\mathrm{OH} 43614$, USA

$\mathrm{Tel}+\mathrm{I} 4 \mid 93831906$

Fax + I 4193831950

Email sharrel.pinto@utoledo.edu
Background: The purpose of this study was to determine the cost savings of a pharmacist-led, employer-sponsored medication therapy management (MTM) program for diabetic patients and to assess for any changes in patient satisfaction and self-reported medication adherence for enrollees.

Methods: Participants in this study were enrollees of an employer-sponsored MTM program. They were included if their primary medical insurance and prescription coverage was from the City of Toledo, they had a diagnosis of type 2 diabetes, and whether or not they had been on medication or had been given a new prescription for diabetes treatment. The data were analyzed on a prospective, pre-post longitudinal basis, and tracked for one year following enrollment. Outcomes included economic costs, patient satisfaction, and self-reported patient adherence. Descriptive statistics were used to characterize the population, calculate the number of visits, and determine the mean costs for each visit. Friedman's test was used to determine changes in outcomes due to the nonparametric nature of the data.

Results: The mean number of visits to a physician's office decreased from 10.22 to 7.07. The mean cost of these visits for patients increased from $\$ 47.70$ to $\$ 66.41$, but use of the emergency room and inpatient visits decreased by at least 50\%. Employer spending on emergency room visits decreased by $\$ 24,214.17$ and inpatient visit costs decreased by $\$ 166,610.84$. Office visit spending increased by $\$ 11,776.41$. A total cost savings of $\$ 179,047.80$ was realized by the employer at the end of the program. Significant improvements in patient satisfaction and adherence were observed.

Conclusion: Pharmacist interventions provided through the employer-sponsored MTM program led to substantial cost savings to the employer with improved patient satisfaction and adherence on the part of employees at the conclusion of the program.

Keywords: costs, patient satisfaction, adherence, pharmaceutical care, diabetes

\section{Introduction}

Diabetes is a major chronic disease both locally and globally. Almost $2.8 \%$ of the global population and 23.6 million people in the US alone are estimated to have the disease. ${ }^{1,2}$ It is also a major cause of mortality and ranks as the sixth leading cause of death in the US. ${ }^{3}$ The disease alone can have a major impact on quality of life, but this effect is compounded further by associated comorbid conditions and complications. The risk of complications is made worse by lack of diagnosis of diabetes in its early stages. It has been estimated that almost $25 \%$ of diabetics in the US do not even know that they have the condition. ${ }^{2}$ Because the early stages of the disease may remain unrecognized, many people would have diabetes-related complications prior 
to diagnosis. ${ }^{4}$ Another concerning fact with diabetes is its known association with hypertension and hyperlipidemia, which further increases the risk of complications. ${ }^{5}$

For these reasons, the disease has a significant cost burden, with approximately $\$ 116$ billion in direct medical costs and $\$ 58$ billion in indirect costs such as work loss, disability, and premature mortality, totaling $\$ 174$ billion in $2007 .^{2}$ It has also been estimated that diabetic patients spend almost 2.3 times more on health care services than those without diabetes. $^{2}$ The majority of the costs are as result of hospital inpatient care, while antidiabetic medication and supplies, prescriptions to treat complications of diabetes, and physician office visits are considered other major contributors. ${ }^{2}$ Given that most patients with diabetes are of working age and engaged in some form of employment, the cost burden of the disease is substantial for employers. ${ }^{6}$ In 2007, diabetes was found to be the cause of 15 million work days lost to employers. ${ }^{7}$ Reduced productivity at work due to a health condition ("presenteeism") caused by seven major chronic conditions including diabetes accounts for approximately $\$ 1.1$ trillion in losses. ${ }^{8}$

Finding ways to reduce the cost burden resulting from chronic disease in employees is becoming a very important issue for employers as they strive to reduce costs. Because health care resources are limited, a range of interventions could be utilized as potential cost-saving measures. ${ }^{9}$ This has led to an increase in the number of employers turning towards disease management programs as a potential resource in the past decade. ${ }^{10}$ As employers look for various avenues to lower cost, use of pharmacist-led interventions can serve as a tool in patients with chronic diseases.

Medication therapy management (MTM) programs have already been shown to have positive effects on the clinical outcome for patients. ${ }^{11-13}$ These programs include personalized medication review, creation of a medication action plan, and clinical and lifestyle interventions, with all these components aiming to lead to target clinical goal attainment by patients. ${ }^{13}$ While intensive glycemic control has been shown to have differing cost-effectiveness based on age at the time of diagnosis, lifestyle modification has been stated to be the most cost-effective and is used as primary prevention. ${ }^{9}$ Medication adherence also plays a significant role in determining the cost burden of chronic disease because it is known that, even in the presence of effective regimens, lack of adherence limits the impact of treatment. Research has shown that half of all patients do not adhere faithfully to their treatment regimens. ${ }^{14}$ In another study, it was determined that if adherence could be improved from $50 \%$ to $100 \%$, there would be a substantial reduction in hospitalization and emergency visits. ${ }^{15}$ Therefore, pharmacist-led interventions that improve adherence can also help in reducing the costs of health care.

While the costs of an interventional strategy, such as an MTM program, remain a major issue for employers when attempting to implement these programs, patient satisfaction is also a significant factor in assessing their value. ${ }^{16}$ Satisfied patients are more likely to adhere to their regimens and show greater continuity with regard to appointments. ${ }^{16}$ Therefore, understanding patient satisfaction can help support the overall effectiveness of such a program and is essential for understanding how to improve MTM programs. ${ }^{16}$ Studies have shown that pharmacist-led services reduce the costs for patients. ${ }^{17,18}$ For example, the Asheville Project, a pharmacist-led employer-sponsored program, found that although patients who received pharmaceutical care services had increased prescription costs annually, their direct medical costs decreased. By the end of the project, insurance claims decreased by a mean of $\$ 6502$ per patient per year. ${ }^{18}$ Similar results have been reported elsewhere. ${ }^{17}$

While studies in the literature have shown that provision of MTM in the pharmacy helps decrease the costs of health care, there is limited evidence to show its value to both employer and employees. The current study sought to determine if any cost savings could be realized by employers as a result of health care utilization by employees participating in pharmacist-led MTM programs. Overall quality of care is a high priority for most employees, and satisfaction levels have been known to influence outcomes for patients. Therefore, the effect of this service on medication adherence and patient satisfaction was also determined in order to understand the overall effectiveness of the intervention program.

\section{Materials and methods Study design and setting}

This study was prospective and pre-post longitudinal in nature. The study participants were enrollees in an employersponsored MTM program being conducted by a coalition of five independent community pharmacies called the Toledo Area Coalition of Independent Pharmacies in Northwest Ohio. Pharmacists provided patient-based care to all enrollees at the different pharmacy sites in the program. Recruitment followed an open enrollment method from January 15, 2008 to September 1, 2010. Qualifying enrollees received incentives in the form of a 90-day supply of their medications at the same co-pay followed by their mail order company, and 100 test strips and lancets per month were distributed 
to the patients at no charge. All counseling sessions were conducted in semiprivate or private counseling areas within a coalition pharmacy.

\section{Inclusion criteria}

Participants in the study included employees, their spouses, and dependants whose primary provider of medical insurance and prescription coverage was the City of Toledo. Participants diagnosed with type 2 diabetes, have been on medication or been administered a new prescription for its treatment, have appropriate means of transport to a participating site, and be able to read and understand English. Any person not meeting any one of the above criteria was excluded from the study. All patients who met the inclusion criteria were tracked in the program for one year after enrollment. This study was approved by the biomedical institutional review board at the University of Toledo.

\section{Visit descriptions}

Patient visits and counseling sessions with pharmacists for the study period were staggered to take place at 2-4 weeks, and 3, 6, 9, and 12 months following the baseline visit. The baseline visit was used to collect personal and demographic information, and to obtain informed consent and a comprehensive list of medications. These data were collected by a trained pharmacy technician without involvement of the pharmacist. This preliminary visit was followed by the initial visit with the pharmacist who recorded clinical markers, conducted a full review of medication, suggested suitable lifestyle and clinical interventions based on clinical outcome for the patient, and formulated a medication action plan to set goals for the patient. Following this visit, the pharmacist communicated with the patient's physician to make them aware of any abnormal laboratory values obtained or make suggestions regarding potential pharmacological intervention. All subsequent visits with the pharmacist were scheduled at intervals of 3 months and involved follow-up medication review, continuous assessment of the health care plan to ensure that patients were adherent with their medication, and assessment of whether the goals that had been set were being met and setting up of new goals as needed. Review of goals and resolving issues that came up in between visits or during the prior session were also done at each follow-up visit.

\section{Study measures}

Economic costs were defined as the amount in dollars spent by the employer on the employee, spouse, and their dependants before and after joining the program. The pre-joining costs were calculated by obtaining all utilization costs for one year before entering the program. All post-costs were calculated for one year following enrollment. Utilization and associated costs were identified by the number and cost of physician office visits, emergency room visits, and inpatient visits or hospitalizations. Total costs were defined as the sum of the aforementioned three different forms of health care utilization.

Patient satisfaction was defined as satisfaction with the pharmacist, pharmacy, and pharmacy staff, and was determined using a 34-item survey with three corresponding sections estimated to take 3-7 minutes to complete. The patient satisfaction instrument was developed by the researchers using reliable and validated surveys which were already in existence. ${ }^{19-21}$ Satisfaction was measured on a five-point Likert scale (1 representing "strongly disagree" and 5 representing "strongly agree"). Adherence with medications was measured using a modified Morisky scale which asks patients to rate their response on a scale of 0-4 (0 represents "never" and 4 represents "always"). The Morisky scale is commonly used to determine adherence with medication. Face and content validity was determined by a panel of practicing clinical pharmacists and University of Toledo faculty members who had relevant experience in the field of research. Patient satisfaction and patient adherence surveys were administered at 3 and 9 months and were completed by the patient at either the pharmacy site or mailed back to the pharmacy.

\section{Data analyses}

After receiving the surveys back from the patient, a copy was sent to the research personnel at the Pharmaceutical Care and Outcomes Research Laboratory at the University of Toledo. All information collected was entered into the Statistical Package for the Social Sciences version 16.0 (SPSS Inc, Chicago, IL). A data management specialist for the City of Toledo provided economic data on the enrollees in the form of a Microsoft Excel spreadsheet. The data were then deidentified, cleaned, and imported into SPSS version 16.0 for analysis. Descriptive statistics were used to characterize the population and to calculate the number of visits and the mean costs associated with these visits. Patient responses were translated into composite scores for both patient satisfaction and adherence. Given the nonparametric nature of the data, the Friedman test was used to analyze outcomes, ie, assessing changes in scores across multiple time points (baseline, 3 months, and 9 months). 


\section{Results}

One hundred and one patients were enrolled into the MTM program. Economic costs were analyzed for patients whose data were available for the one-year study period. Changes in number of visits and mean costs are shown in Table 1 . The number of patients who had a physician office visit increased from 54 to 67 after joining the program. The average number of physician office visits decreased from 10.22 to 7.07 , and mean costs for these patients increased from $\$ 47.70$ to $\$ 66.41$. Utilization of emergency room visits and inpatient visits decreased by at least $50 \%$. A corresponding decrease in spending on emergency room visits and hospitalization was seen from the perspective of the employer, while a slight increase in physician office visit spending was observed. Costs for all visits and total costs are shown in Table 2 . Office visit costs were found to increase by $\$ 11,776.41$, but cost savings of $\$ 24,214.17$ and $\$ 166,610.84$ were realized for emergency room visits and inpatient visits. Overall, a substantial cost savings of $\$ 179,047.80$ was found when the total costs for the employees, their spouses, and dependants were taken into account.

Patient satisfaction scores were analyzed looking at changes across time for each of the three domains and for the composite satisfaction score (Table 3). Thirty-nine patients completed the survey at all three time points and were included in the final analysis. A significant improvement was seen for all domains, ie, experience with the pharmacist $(P<0.001)$, experience with the pharmacy $(P<0.001)$, experience with pharmacy staff $(P=0.002)$, and overall satisfaction $(P=0.003)$. Patient adherence was reported on a scale of $1-5$, with lower scores representing higher adherence. Adherence was found to decrease marginally for the study population at 6 months, but improved at 12 months. The overall improvement in adherence was found to be statistically significant $(P=0.003)$.

\section{Discussion}

In the present era of health care reform, professional organizations such as The American College of Clinical Pharmacy recognize that pharmaceutical services will be distinguished by the presence of three principal values, ie, managing and lowering of costs, increasing patient satisfaction, and improving patient outcomes..$^{22}$ In our employer-sponsored MTM program, we focused on these three core values to show employers the value of establishing such pharmacist-led programs for their employees. Elements of services provided by pharmacists are already known to have economic benefits for patients. ${ }^{23}$ However, evidence of economic benefits from MTM services, which differ slightly from clinical pharmacy services, have only recently started appearing on the horizon..$^{12,24}$

In this study, we found that pharmacist-led interventions led to a decrease in spending on emergency room visits and hospitalizations from the perspective of the employer and an increase in spending on office visits. Pharmacists in the program encouraged patients to visit a specialty care physician as per the recommended guidelines. ${ }^{25}$ Therefore, the observed increase in number and average office visit costs could potentially be explained by the increased number of specialty visits (such as to a podiatrist or ophthalmologist) that the employees would have made after joining the program. There is also evidence in the literature that diabetic patients are less likely to make office visits if they are managing their condition well. ${ }^{26}$ Because most of the patients in our study population were not at target to begin with or for most of the duration of the program, the patients who were not visiting a physician regularly would have been doing so after intervention by the pharmacist, while utilization patterns were likely to have remained constant. Office visits were selfreported by employees and documented by the pharmacist, but are not presented as part of this study. These specialty visits may cost more to the patient, which may have attributed to the increase in average cost per visits, but these visits also help in early detection of disease-related problems and may help in reducing future health care utilization costs arising from complications. ${ }^{27,28}$ The decreased emergency room visits and hospitalization costs seen in this program implies better management of the disease by patients. The risk of hospitalization has been shown to decrease when the severity of diabetes and its complications are reduced. ${ }^{29}$ For both of these variables, the number of users decreased by almost $50 \%$. These results indicate an improvement in clinical outcome for patients and a reduction in complications.

Table I Mean costs and number of visits pre-joining and post-joining the City of Toledo medication therapy management program

\begin{tabular}{lllll}
\hline Variable & $\begin{array}{l}\text { Average cost } \\
\text { (pre-joining) }\end{array}$ & $\begin{array}{l}\text { Average number } \\
\text { of visits (pre-joining) }\end{array}$ & $\begin{array}{l}\text { Average cost } \\
\text { (post-joining) }\end{array}$ & $\begin{array}{l}\text { Average number } \\
\text { of visits (post-joining) }\end{array}$ \\
\hline Office visit $(n=54)$ & 47.70 & 10.22 & $66.41(n=67)$ & 7.07 \\
Emergency room visit $(n=23)$ & 1378.33 & 1.87 & $1722.08(n=12)$ & 1.33 \\
Inpatient visits $(n=10)$ & 16002.16 & 1.60 & $17016.19(n=3)$ & 1.33 \\
\hline
\end{tabular}


Table 2 Overall costs pre-joining and post-joining the City of Toledo medication therapy management program

\begin{tabular}{llll}
\hline Variable & $\begin{array}{l}\text { Costs pre-joining } \\
\text { (in US dollars) }\end{array}$ & $\begin{array}{l}\text { Costs post-joining } \\
\text { (in US dollars) }\end{array}$ & $\begin{array}{l}\text { Cost differences } \\
\text { (in US dollars)* }\end{array}$ \\
\hline Office visits & $22,946.45$ & $34,722.91$ & $11,776.41$ \\
Emergency room visits & $56,381.80$ & $32,167.63$ & $-24,214.17$ \\
Inpatient visits & $222,522.42$ & $55,911.58$ & $-166,610.84$ \\
Total costs & $301,849.92$ & $122,802.12$ & $-179,047.80$ \\
\hline
\end{tabular}

Notes: *Negative values indicate cost savings. Includes costs for all patients enrolled in the program.

A factor that may have led to the observed decrease in utilization costs was the self-reported improvement in patient adherence with therapy. Increased adherence with antidiabetic medication has been found to be associated with significant reductions in net health care $\operatorname{costs}^{28,30}$ and with optimal clinical outcomes..$^{31}$ Interestingly, patient adherence was found to diminish at the 3-month time point, but then improved significantly by the end of the study. This transient decrease in adherence may have been a result of an increase in the number of medications prescribed after joining the program. ${ }^{32}$ Another explanation for nonadherence could be that some of the patients missed their first appointment with the pharmacist 2-3 weeks following the baseline visit. These patients would not have received appropriate diseaserelated education from the pharmacist, and this might have influenced their adherence levels because there is a known association between nonadherence in the diabetic population and time since diabetes education. ${ }^{33}$

From the employer's perspective, it is not only important to look at the overall reduction in costs resulting from the program, but also at whether the employees were satisfied and perceived this new service as a valuable addition to their usual care. Therefore, patient satisfaction is a key variable for determining the value of a health care program. In the past, it has often been used as a one-dimensional outcome measure looking only at overall satisfaction with the service. ${ }^{16,34,35}$ Researchers in this study looked at satisfaction as a composite of the individual domains of pharmacist, pharmacy, and pharmacy staff. Therefore, it was possible to clarify whether patients were satisfied with one or all of the components of the MTM program. We found that patient satisfaction levels improved significantly from baseline on all domains of the pharmacy satisfaction survey at 9 months. An interesting result was that patients with an improved $\mathrm{HbA}_{1 \mathrm{c}}$ tended to be more satisfied than those who did not. Previous research has shown that patients who reach an optimal $\mathrm{HbA}_{1 \mathrm{c}}$ are more satisfied and more adherent with medication. ${ }^{31}$ Determination of overall quality of care from the patient's point of view may incorporate the nontechnical aspects of medical care. ${ }^{36}$ Because the survey instrument used in this study measured various domains of satisfaction, rather than a single domain, patient satisfaction was a global measure and could be considered accurate.

Patient satisfaction may help employers to make decisions about scaling up the program and when determining further recruitment strategies. The results of this study are important with regard to estimating the cost savings possible if an employer decides to implement this program in a similar employee population. Few studies in the past have addressed increased reimbursements for pharmacists and a positive return on investment for stakeholders, such as employers participating in MTM programs. ${ }^{37,38}$ As seen in this study, MTM programs may helps to lower health care costs to employers. The findings of this research may encourage employers to use pharmacists as a valuable resource when looking to improve the health of their employees and to save costs.

With regard to limitations, this study did not look at the implementation costs of the MTM program to the pharmacy

Table 3 Change in patient satisfaction and patient self-reported adherence

\begin{tabular}{lllll}
\hline Survey (n) & $\begin{array}{l}\text { Mean } \pm \text { SD score } \\
\text { (baseline) }\end{array}$ & $\begin{array}{l}\text { Mean } \pm \text { SD score } \\
\text { (3-month visit) }\end{array}$ & $\begin{array}{l}\text { Mean } \pm \text { SD score } \\
\text { (9-month visit) }\end{array}$ \\
\hline Experience with pharmacist (39) & $3.08 \pm 1.09$ & $4.20 \pm 0.71$ & $4.54 \pm 0.66$ & $\begin{array}{l}\text { P value } \\
\text { Experience with pharmacy (39) }\end{array}$ \\
Experience with pharmacy staff (39) & $3.35 \pm 1.21$ & $4.16 \pm 0.68$ & $4.42 \pm 0.52$ & 0.000 \\
Overall patient satisfaction (39) & $3.79 \pm 1.30$ & $4.50 \pm 0.75$ & $4.62 \pm 0.49$ & 0.000 \\
Patient adherence (35) & $3.26 \pm 1.07$ & $4.22 \pm 0.66$ & $4.51 \pm 0.53$ & 0.000 \\
\hline
\end{tabular}

Notes: Patient satisfaction was measured on a scale of I-5. A score of I represents patients highly unsatisfied and 5 highly satisfied with pharmacy services. Patient adherence was also measured on a scale of I-5. A score of I represents patients were always adherent in taking their medications and score of 5 represents they were never adherent. Abbreviation: SD, standard deviation. 
because our cost calculations were from the perspective of the employer. Also, indirect costs, resulting from savings on absenteeism and improved quality of life, were not calculated. Therefore, showing a return on investment from the perspective of the pharmacy or employer was not possible in this study. Substantial cost savings were realized solely by reducing direct medical health care costs, and the overall cost savings reported may be an underestimate because other indirect costs were not addressed. Future research could address the actual return-on-investment from the employer's perspective. Further, these cost savings were realized despite subject retention issues. Almost $50 \%$ of the patients in the program failed to complete the full one-year study period, which impacted the statistical power of the study. As mentioned previously, enrollees were provided with incentives and the pharmacist made reminder phone calls about appointments. The dropout rate might have been higher if these measures were not in place. Another limitation of this study was that adherence was measured as a self-reported outcome, and research has shown that self-reporting may lead to recall bias and underestimation of adherence, but these measures have still been found to be useful indicators for measuring patient adherence with treatment. ${ }^{39,40}$

\section{Conclusion}

This MTM program had numerous positive outcomes for both employers and employees. Employers realized overall cost savings of $\$ 179,047.80$, while employees showed a significant increase in patient satisfaction and self-reported adherence with medication. The positive economic and humanistic results of this study provide supporting evidence for implementation of employer-sponsored, pharmacist-led MTM programs.

\section{Acknowledgments}

The study was funded by a seed grant from The National Business Coalition on Health. The authors acknowledge the City of Toledo, FrontPath Health Coalition, and the Toledo Area Coalition of Independent Pharmacies, specifically Bryan Coehrs and Chuck Riepenhoff, for their time and knowledge in providing clinical services, and Dennis Newsom and Steven Martin for their administrative and general support.

\section{Disclosure}

The authors report no conflicts of interest in this work.

\section{References}

1. Wild S, Roglic G, Green A, et al. Global prevalence of diabetes: estimates for the year 2000 and projections for 2030. Diabetes Care. 2004;27:1047-1053.

2. [No authors listed]. Economic costs of diabetes in the US in 2007. Diabetes Care. 2008;31:596-615.

3. Centers for Disease Control and Prevention. National Diabetes Fact Sheet: General Information and National Estimates on Diabetes in the United States, 2003, Revised Edition. Atlanta, GA: Centers for Disease Control and Prevention; 2004.

4. Spijkerman AM, Dekker JM, Nijpels G, et al. Microvascular complications at time of diagnosis of type 2 diabetes are similar among diabetic patients detected by targeted screening and patients newly diagnosed in general practice: the Hoorn screening study. Diabetes Care. 2003;26:2604-2608.

5. Mann DM, Ponieman D, Leventhal H, et al. Predictors of adherence to diabetes medications: the role of disease and medication beliefs. J Behav Med. 2009;32:278-284.

6. Durden ED, Alemayehu B, Bouchard JR, et al. Direct health care costs of patients with type 2 diabetes within a privately insured employed population, 2000 and 2005. J Occup Environ Med. 2009;51:1460-1465.

7. American Diabetes Association. Direct and indirect costs of diabetes in the United States, 2009. Available from: http://www.diabetesarchive. net/diabetes-statistics/cost-of-diabetes-in-us.jsp. Accessed October 13, 2010.

8. Milken Institute. An unhealthy America: the economic burden of chronic disease, 2007. Available from: http://www.milkeninstitute.org/ publications/publications.taf? function=detail $\& I D=38801020 \&$ cat $=$ res rep. Accessed January 30, 2013.

9. Li R, Zhang P, Barker LE, et al. Cost-effectiveness of interventions to prevent and control diabetes mellitus: a systematic review. Diabetes Care. 2010;33:1872-1894.

10. Mercer Health and Benefits. Mercer's 2006 National Survey of Employer-Sponsored Health Plans. New York, NY: Mercer Health and Benefits; 2006.

11. Osterberg L, Blaschke T. Adherence to medication. $N$ Engl J Med. 2005;353:487-497.

12. Isetts BJ, Schondelmeyer SW, Artz MB, et al. Clinical and economic outcomes of medication therapy management services: the Minnesota experience. J Am Pharm Assoc. 2008;48:203-211.

13. American Pharmacists Association; National Association of Chain Drug Stores Foundation. Medication therapy management in pharmacy practice: core elements of an MTM service model (version 2.0). $\mathrm{J} \mathrm{Am}$ Pharm Assoc. 2008;48:341-353.

14. Cutler DM, Everett W. Thinking outside the pillbox - medication adherence as a priority for health care reform. N Engl J Med. 2010; 362:1553-1555.

15. Encinosa WE, Bernard D, Dor A. Does prescription drug adherence reduce hospitalizations and costs? The case of diabetes. Adv Health Econ Health Serv Res. 2010;22:151-173.

16. Moczygemba LR, Barner JC, Brown CM, et al. Patient satisfaction with a pharmacist-provided telephone medication therapy management program. Res Social Adm Pharm. 2010;6:143-154.

17. Monte SV, Slazak EM, Albanese NP, et al. Clinical and economic impact of a diabetes clinical pharmacy service program in a university and primary care-based collaboration model. J Am Pharm Assoc. 2009;49:200-208.

18. Cranor CW, Bunting BA, Christensen DB. The Asheville Project: long-term clinical and economic outcomes of a community pharmacy diabetes care program. J Am Pharm Assoc. 2003;43:173-184.

19. Larson LN, Rovers JP, MacKeigan LD. Patient satisfaction with pharmaceutical care: update of a validated instrument. J Am Pharm Assoc (Wash). 2002;42:44-50.

20. Doucette WR, McDonough RP. Beyond the 4Ps: using relationship marketing to build value and demand for pharmacy services. $J$ Am Pharm Assoc (Wash). 2002;42:183-193. 
21. Hooker RS, Ray W. Patient satisfaction: comparing physician assistants, nurse practitioners, and physicians. The Permanente Journal. 1997;1:5.

22. Hammond RW, Schwartz AH, Campbell MJ, et al. Collaborative drug therapy management by pharmacists - 2003. Pharmacotherapy. 2003;23:1210-1225.

23. Schumock GT, Butler MG, Meek PD, et al. Evidence of the economic benefit of clinical pharmacy services: 1996-2000. Pharmacotherapy. 2003;23:113-132.

24. Bunting BA, Cranor CW. The Asheville Project: Long-term clinical, humanistic, and economic outcomes of a community-based medication therapy management program for asthma. J Am Pharm Assoc (2003). 2006;46:133-147.

25. American Diabetes Association: Clinical practice recommendations 2002. Diabetes Care. 2002;25 Suppl 1:S1-S147.

26. Shetty S, Secnik K, Oglesby AK. Relationship of glycemic control to total diabetes-related costs for managed care health plan members with type 2 diabetes. J Manag Care Pharm. 2005;11:559-564.

27. Ronnemaa T, Hamalainen H, Toikka T, et al. Evaluation of the impact of podiatrist care in the primary prevention of foot problems in diabetic subjects. Diabetes Care. 1997;20:1833-1837.

28. Gulliford MC, Latinovic R, Charlton J. Diabetes diagnosis, resource utilization, and health outcomes. Am J Manag Care. 2008;14:32-38.

29. Young BA, Lin E, Von Korff M, et al. Diabetes complications severity index and risk of mortality, hospitalization, and healthcare utilization. Am J Manag Care. 2008;14:15-23.

30. Sokol MC, McGuigan KA, Verbrugge RR, et al. Impact of medication adherence on hospitalization risk and healthcare cost. Med Care. 2005;43:521-530.

31. Alvarez-Guisasola F, Tofe-Povedano S, Krishnarajah G, et al. Hypoglycaemic symptoms, treatment satisfaction, adherence and their associations with glycaemic goal in patients with type 2 diabetes mellitus: findings from the Real-Life Effectiveness and Care Patterns of Diabetes Management (RECAP-DM) Study. Diabetes Obes Metab. 2008;10 Suppl 1:25-32.
32. Park KK, Kim BW, Kam S, et al. Factors that affect medication adherence in elderly patients with diabetes mellitus. Korean Diabetes $J$. 2010;34:55-65.

33. Kalyango JN, Owino E, Nambuya AP. Non-adherence to diabetes treatment at Mulago Hospital in Uganda: prevalence and associated factors. Afr Health Sci. 2008;8:67-73.

34. Pourat N, Kagawa-Singer M, Wallace SP. Are managed care Medicare beneficiaries with chronic conditions satisfied with their care? J Aging Health. 2006;18:70-90.

35. Christensen DB, Roth M, Trygstad T, et al. Evaluation of a pilot medication therapy management project within the North Carolina State Health Plan. J Am Pharm Assoc. 2007;47:471-483.

36. Clark PA. Medical practices' sensitivity to patients' needs. Opportunities and practices for improvement. J Ambul Care Manage. 2003;26: 110-123.

37. Barnett MJ, Frank J, Wehring H, et al. Analysis of pharmacist-provided medication therapy management (MTM) services in community pharmacies over 7 years. J Manag Care Pharm. 2009;15:18-31.

38. Ramalho de Oliveira D, Brummel AR, Miller DB. Medication therapy management: 10 years of experience in a large integrated health care system. J Manag Care Pharm. 2010;16:185-195.

39. Grymonpre RE, Didur CD, Montgomery PR, et al. Pill count, selfreport, and pharmacy claims data to measure medication adherence in the elderly. Ann Pharmacother. 1998;32:749-754.

40. Vik SA, Maxwell CJ, Hogan DB. Measurement, correlates, and health outcomes of medication adherence among seniors. Ann Pharmacother. 2004;38:303-312.
ClinicoEconomics and Outcomes Research

\section{Publish your work in this journal}

ClinicoEconomics \& Outcomes Research is an international, peerreviewed open-access journal focusing on Health Technology Assessment, Pharmacoeconomics and Outcomes Research in the areas of diagnosis, medical devices, and clinical, surgical and pharmacological intervention. The economic impact of health policy and health systems

\section{Dovepress}

organization also constitute important areas of coverage. The manuscript management system is completely online and includes a very quick and fair peer-review system, which is all easy to use. Visit http://www.dovepress.com/testimonials.php to read real quotes from published authors. 